\title{
Comparative Effects of Arabinosyl Nucleosides upon the Postnatal Growth and Development of the Rat
}

\author{
JACK M. FISHAUT, JAMES D. CONNOR, ${ }^{(32)}$ AND PETER W. LAMPERT \\ Departments of Pediatrics and Pathology, University of California, San Diego, La Jolla, California, USA
}

Extract

Some arabinosyl nucleosides and halogenated deoxyribosides are currently being used as antiviral chemotherapeutic agents. The halogenated deoxyriboside, 5-fluoro-2'-deoxyuridine (FUDR), the arabinosyl nucleoside, 3- $\beta$-D-arabinofuranosylcytosine (Ara-C), and other antimetabolites are known to interfere specifically with growth and cellular organization of the cerebellum postnatally. It has been shown that there is a difference in toxicity in in vitro tissue culture, adult animals and humans, between Ara-C and adenine arabinoside (Ara-A). Therefore, we compared these nucleosides and the deaminated metabolite of Ara-A, 9- $\beta$-D-arabinofuranosylhypoxanthine (hypoxanthine arabinoside, Ara-Hx), by administering varying doses of each nucleoside to two litters each (19-25 animals) of 2-day-old white rats. The Ara-C was given in doses of $3,5,10$, and $15 \mathrm{mg} / \mathrm{kg}$; the Ara-A $3,5,10,20,30$, and $50 \mathrm{mg} / \mathrm{kg}$; and the Ara-Hx 10 and 20 $\mathrm{mg} / \mathrm{kg}$. Injections were given on days $2,3,4$, and 5 . Additional litters were given injections of saline solution and used as controls. All animals were observed for survival, weight gain, vigor, and developmental motor behavior. The cerebellum was examined grossly and histologically at various intervals. The Ara-A and Ara-Hx-treated animals differed in no way in any of the variables studied from saline-injected controls. There was a definite increase in morbidity and mortality among the Ara-C-treated animals. Those receiving the lowest dose of Ara-C $(3 \mathrm{mg} / \mathrm{kg})$ were retarded in growth and there was disorganization of the cytoarchitecture of the cerebellum early in development; however, repair occurred and no behavioral or developmental abnormalities resulted in mature animals. With the higher doses of Ara-C $(>5 \mathrm{mg} / \mathrm{kg})$, profound disruption of cerebellar cytoarchitecture occurred; both gross neurologic abnormalities and marked growth retardation developed in adult animals which survived.

\section{Speculation}

There are problems with assuming direct or unifying structure-action relations among chemotherapeutic agents. Efforts should be exerted to determine accurately the kinetic parameters and therapeutic index for each new drug as it comes into use. The data presented here show that, in doses effective against DNA viral infection, the purine nucleosides Ara-A and Ara-Hx did not substantially impair DNA replication and inhibit cellular function in the rat cerebellum in comparison to the pyrimidine nucleoside, Ara-C. It is interesting to speculate that Ara-A may be incorporated preferentially into viral nucleic acid by viral enzymes, as in the case of 5-bromodeoxycytidine by herpes virus-infected cells.
Assuming that Ara-A is proven further to be an effective antiviral compound, the lack of toxicity upon rapidly replicating cells of various systems gives it an obvious advantage in comparison with other compounds which inhibit DNA viral replication.

In part, advances in molecular biology have come about as the result of detailed study of biochemical and genetic events. Methods of study have included the use of metabolic inhibitors, some of which have been found to block synthesis of new specific viral structural materials resulting in selective suppression of replicative processes. By this means, a moderate number of prospective chemotherapeutic agents have been made available for study in viral infections of animals and for potential clinical use in humans. One of the limitations of use of antiviral compounds is directly the result of interaction between the cells of the host and the antibiotic. Thus, there are many examples of chemicals which, in in vitro systems, effectively or totally prevent viral replication, but cannot be used in clinical trials beause of cellular toxicity. The chances of cellular damage in rapidly developing organs in the immature host, with permanent sequelae as a result, are greater than in the mature animal. Therefore, we agree with Langman and associates (14) that there are dangers implicit in treating newborn infants for viral infections with compounds that are known to inhibit or interrupt DNA replication, except in the case where inhibition is specific for viral replication and cellular replication is spared (7).

The treatment of herpetic and cytomegalovirus infections in neonates with inhibitors of DNA synthesis occurs in a setting of rapid nucleic acid synthesis and cell division. Repair may quickly follow suppression of cellular DNA synthesis in some organs; for example, in the gastrointestinal and urinary tracts. However, in organs of limited regenerative capacity, such as the central nervous system, permanent damage may occur. This is particularly true where cellular proliferation is strongly associated with differentiation and ontogeny (1).

In the postnatal cerebellum of smaller animals, there occurs extensive replicative activity along with cellular migration and maturation (9). In rodents, interference with the rapid development of the postnatal cerebellum may result from various injuries, including that induced by the use of cyclophosphamide (Cytoxan) (18), FUDR (14) and Ara-C (8) (Cytosar (28)).

Another arabinosyl nucleoside Ara-A, has been introduced recently as an antiviral compound, effective in vitro against large DNA virus infections, including Herpes virus hominis types 1 and 2, varicella-zoster, vaccinia virus, and cytomegalo- 
virus (25). This drug has low toxicity for small animals (13) but its effects upon postnatal development have not been examined. Therefore, this study was designed to compare the effects of Ara-A and its deaminated derivative, Ara-Hx, with those of Ara-C on the newborn rat. The rat was a species chosen for this study because much is known about the normal development including cerebellar growth and maturation (27).

Ara-A is known to be rapidly deaminated by the mammalian enzyme, adenosine deaminase to Ara-Hx (4). Therefore, the in vitro activity of Ara-A may depend upon the plasma and tissue concentration of Ara-Hx. For this reason, we decided to examine the antireplicative activity of Ara-Hx as well as Ara-A.

\section{MATERIALS AND METHODS}

Different duplicate litters of 2-day-old Sprague-Dawley rats received injections intraperitoneally with a 1-cc tuberculin syringe filled with lactated Ringer's solution containing either Ara-A (29) (at final dosage of 3, 5, 10, 20, and $30 \mathrm{mg} / \mathrm{kg}$ ), Ara-Hx (29) (10 and $20 \mathrm{mg} / \mathrm{kg})$, or Ara-C (30) (3, 5, 10, and $15 \mathrm{mg} / \mathrm{kg}$ ). Animals received injections once daily for 4 days. A control litter received injections of the vehicle with drugs omitted.

The animals were weighed in a pan balance every 4th day until the age of 60 days. They were observed daily for fatalities and those obviously injured by an injection were discarded from the study. All were examined for evidence of poor feeding, pallor, lethargy, and skin infection. Dying animals were removed from cages when possible to avoid maternal cannibalism. These were scored as fatalities. Individuals were selected at random from each group and killed at $6,10,14,18$, and 22 days of age. Brains of experimental and control animals were rapidly removed and fixed in $10 \%$ buffered formalin for 3 days. They were then divided by a precise sagittal cut, and the dimensions of the cerebellum measured with a micrometer. One-half of each brain was embedded in paraffin and sagittal sections were cut and stained with hematoxylin and eosin. The other fixed hemicerebellum was weighed on a Mettler balance.

To determine the effect of the drugs on motor development, locomotion was evaluated by a simplification of the methods of Wallace and Altman (26) and of Altman et al. (2). All litters were observed daily up to the age of 5 weeks (midadolescence).

Later, another group were given $50 \mathrm{mg} / \mathrm{kg}$ Ara-A and observed for mortality alone.

\section{RESULTS}

The lethality of the three arabinosyl nucleosides to suckling rats is shown in Table 1. All fatalities occurred before the 18 th postnatal day. There were no fatalities among controls, nor were there any drug-induced deaths for those animals treated with less than $20 \mathrm{mg} / \mathrm{kg}$ Ara-A. Mortalities of $3 \%$ and $12 \%$, respectively, were observed for Ara-A at $20 \mathrm{mg} / \mathrm{kg}$ and $30 \mathrm{mg} / \mathrm{kg}$, but these were not statistically significant $\left(\chi^{2}, P<\right.$ 0.05 ). Animals treated with either Ara-A or Ara-Hx showed no signs of poor feeding, lethargy, or pallor. They matured at a normal rate and, by the 4th week, were identical with controls. All animals treated with lowest dose of Ara-C (3 $\mathrm{mg} / \mathrm{kg}$ ) developed normally. Those receiving higher doses of Ara-C developed pustules over the body and head, appeared weak and pale, and fed poorly. In those which survived to adolescence, the pustules crusted and cleared, but hair growth was retarded and coarse.

Comparative growth curves are shown in Figure 1. Included are the control group and the groups receiving Ara-A, 30 $\mathrm{mg} / \mathrm{kg}$; Ara-Hx, $20 \mathrm{mg} / \mathrm{kg}$; and Ara-C, 3, 5, and $10 \mathrm{mg} / \mathrm{kg}$ doses. The $15 \mathrm{mg} / \mathrm{kg}$ Ara-C group is not included, for all animals were dead by the 10 th day. Animals receiving Ara-C failed to grow compared with the saline control, Ara-A, and Ara-Hx animals. An analysis of variance (F test) revealed no statistically significant difference among any of the controls, Ara-A, or Ara-Hx populations $(P<0.05)$.

Figure 2 demonstrates cerebellar weight during the first 3 weeks of life in controls, and in groups treated with Ara-A, Ara-Hx, and Ara-C. Two populations are evident with neither arabinosyl purine affecting cerebellar growth compared with saline-injected controls (Fig. 2, $A$ and $B$ ). At $15 \mathrm{mg} / \mathrm{kg} \mathrm{Ara-C}$, there was little, if any, growth before death at 10 days (Fig. $2 C$ ). At 3,5 , and $10 \mathrm{mg} / \mathrm{kg}$ Ara-C, there was markedly retarded growth of the cerebellum. However, at the lowest dose $(3 \mathrm{mg} / \mathrm{kg})$, the animals did repair and were not damaged as they reached maturity by any of the variables measured. None of the drugs induced grossly obvious impairment in cerebral growth; how ever, the brains were not weighed.

Comparative histopathology further confirmed marked differences in the effects of the nucleosides upon the cerebellum as shown in Figure $3, A, B$, and $C$. The majority of the histologic findings were taken from the most caudad lobe of the cerebellar hemisphere, the uvula. The findings are exemplified by sections of cerebella of animals receiving Ara-A

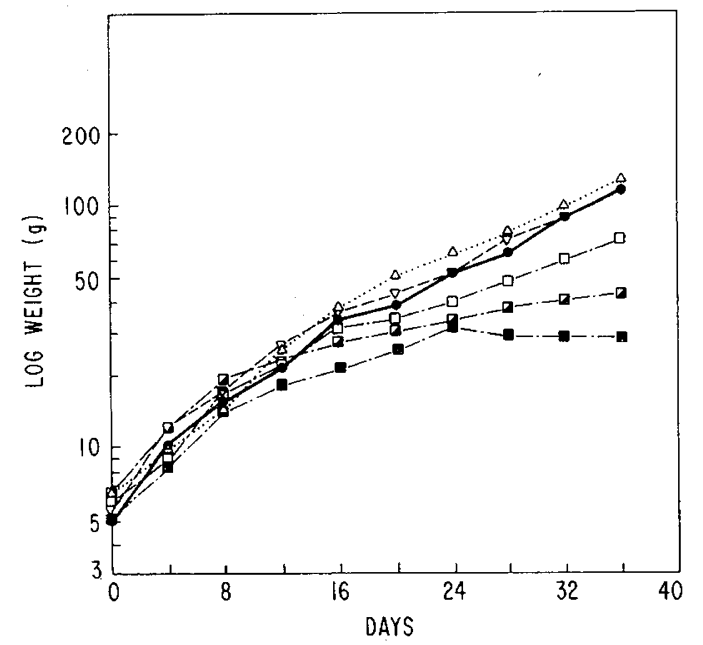

Fig. 1. Effect of arabinosyl nucleosides on the growth of the white rat. $\cdots .$. : adenine arabinoside; $-\cdot \cdots \cdot-$ : cy tosine arabinoside; $--\cdots$ : hypoxanthine arabinoside: —: saline solution; $\square: 3 \mathrm{mg} / \mathrm{kg} ; \mathbf{a}: 5 \mathrm{mg} / \mathrm{kg}$; -: $10 \mathrm{mg} / \mathrm{kg} ; \nabla: 20 \mathrm{mg} / \mathrm{kg} ; \Delta: 30 \mathrm{mg} / \mathrm{kg}$.

Table 1. Lethality of arabinosyl nucleosides to suckling ràts ${ }^{1}$

\begin{tabular}{llllllllllllll}
\hline \multicolumn{1}{c}{ Drug } & \multicolumn{1}{c}{ Ara-A } & \multicolumn{4}{c}{ Ara-Hx } & \multicolumn{3}{c}{ Ara-C } & Control \\
\hline Dose (mg $/ \mathrm{kg})^{2}$ & 3 & 5 & 10 & 20 & 30 & 50 & 10 & 20 & 3 & 5 & 10 & 15 \\
Fatality & $0 / 19$ & $0 / 22$ & $0 / 24$ & $2 / 25$ & $3 / 25$ & $0 / 23$ & $0 / 20$ & $0 / 17$ & $0 / 18$ & $9 / 24$ & $11 / 20$ & $25 / 25^{3}$ & $0 / 20$ \\
Mortality (\%) & 0 & 0 & 0 & 8 & 12 & 0 & 0 & 0 & 0 & 37.5 & 55 & 100 & \\
\hline
\end{tabular}

${ }^{1}$ Ara-A: adenine arabinoside; Ara-Hx: hypoxanthine arabinoside; Ara-C: cytosine arabinoside.

${ }^{2}$ Two-day-old animals received intraperitoneal injections on postnatal days 2 through 5 , containing dose indicated.

${ }^{3}$ All dead by 10 days. 

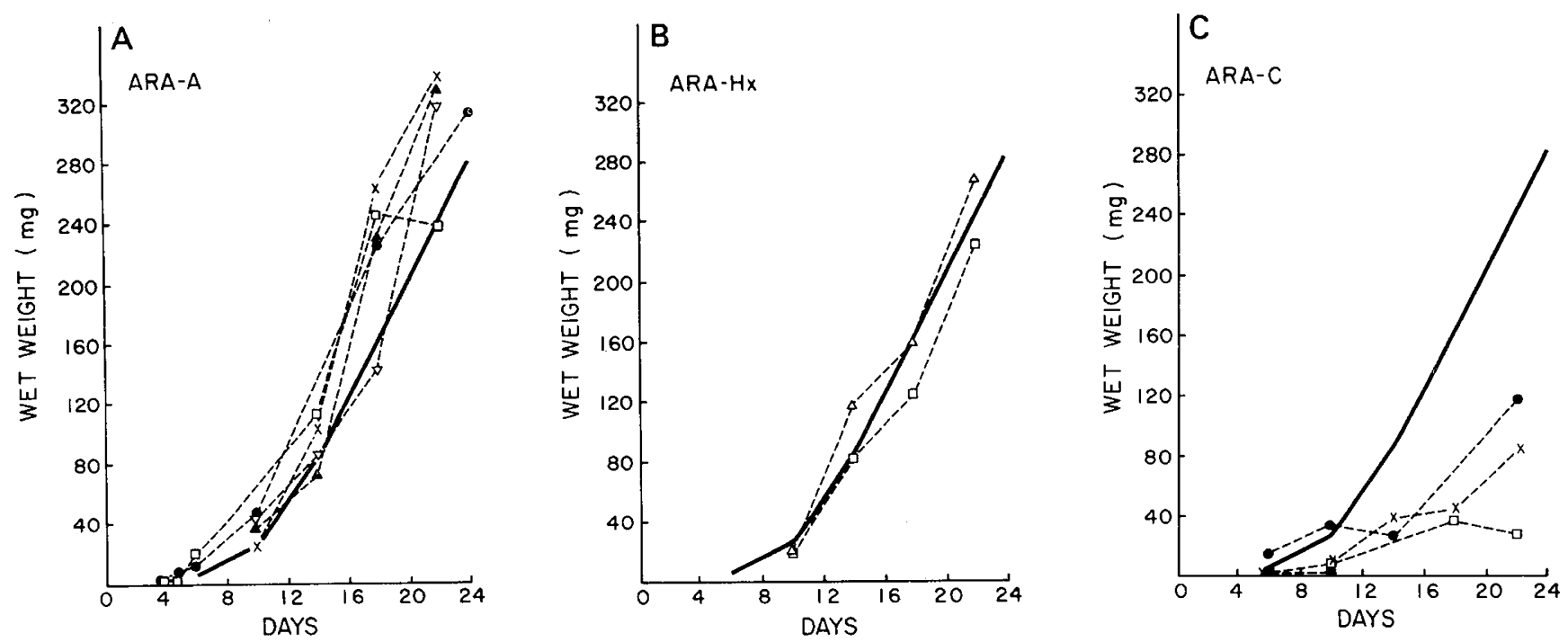

Fig. 2. Effect of arabinosyl nucleosides on growth of the developing cerebelium of the white rat. $A$ : adenine arabinoside; $B$ : hypoxanthine arabinoside; $C$ : cytosine arabinoside; _ _ - : arabinosyl nucleosides; — : saline solution; $\bullet: 3 \mathrm{mg} / \mathrm{kg} ; \mathrm{X}: 5 \mathrm{mg} / \mathrm{kg} ;$ : $: 10 \mathrm{mg} / \mathrm{kg} ; \bullet: 15 \mathrm{mg} / \mathrm{kg} ; \Delta: 20$ $\mathrm{mg} / \mathrm{kg} ; \nabla: 30 \mathrm{mg} / \mathrm{kg}$.

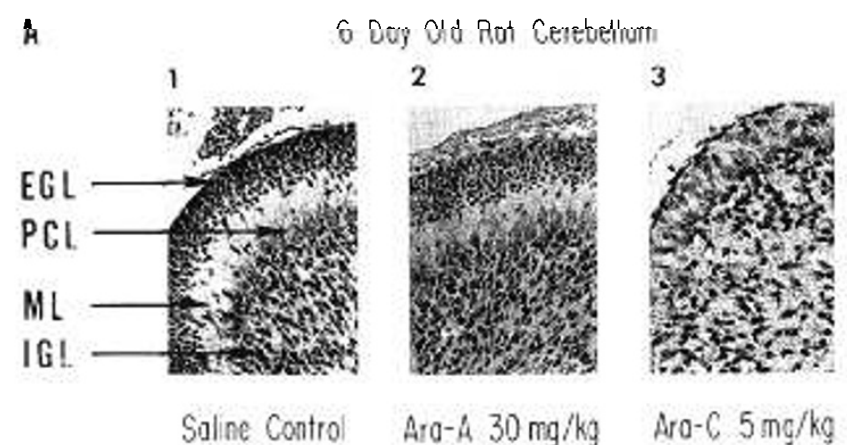

B

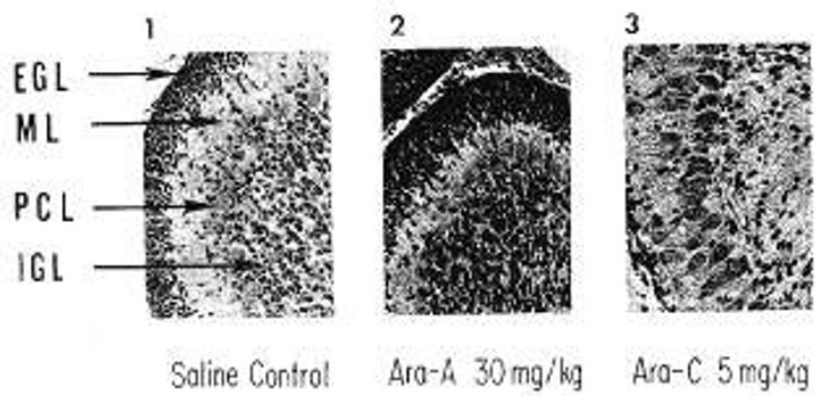

c

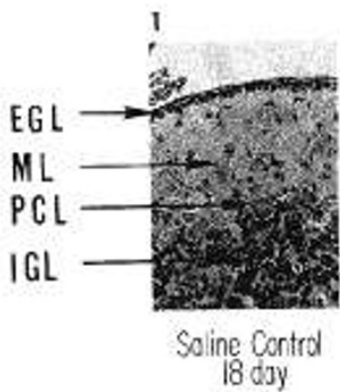

2
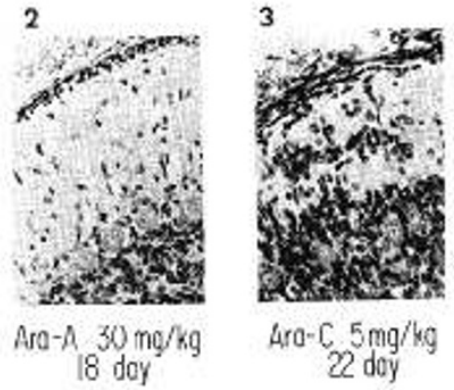

Fig. 3. Comparison of histoarchitecture and cellular content of the cerebellum in white rats receiving injections of normal saline, adenosine arabinoside or cytosine arabinoside at various ages; hemotoxylin and eosin stain; magnification, $\times \quad 500-580$.
$30 \mathrm{mg} / \mathrm{kg}$, Ara-C $5 \mathrm{mg} / \mathrm{kg}$, or vehicle alone and killed on day 6 , 10,18 , or 22 as discussed below.

By the 6th day of postnatal life, the external granulayer (EGL) of the cerebellum is a densely packed stratum 6-8 cells thick. It is separated from the Purkinje cell layer by a definite molecular layer (ML). The Purkinje cells are oriented externally and ordered regularly at the outer surface of the sparsely populated internal granular layer (IGL). The cerebella of animals treated with Ara-A (Fig. 3, $A 2, B 2$, and $C 2$ ) were of normal appearance and were identical to controls (Fig. 3, $A 1$, $B 1$, and $C 1$ ). In contrast, cerebella of Ara-C-treated animals were markedly abnormal as shown in Figure $3 A 3$. The EGL was absent, Purkinje cells were dispersed throughout the ML and cells of the IGL were found in various areas. Moderate abnormalities were present at even the lowest dose, $3 \mathrm{mg} / \mathrm{kg}$.

In the 10-day old animals, cellularity and organization within the cerebellum of those receiving Ara-A and Ara-Hx were identical with controls. In animals receiving $3 \mathrm{mg} / \mathrm{kg}$ Ara-C, repair was obvious at 10 days in the EGL so that it now resembled the cerebellum of day 6 control animals. Purkinje cells, however, remained in disarray. In contrast, only minimal repair had taken place in animals receiving greater than 3 $\mathrm{mg} / \mathrm{kg}$ Ara-C, and there was obvious disorganization.

By day 18 and beyond, the control and Ara-A-treated animals had an essentially adult cerebellum with a sparse EGL, a broad ML, and a densely packed IGL (Fig. 3, Cl and C2). In contrast, cerebella of Ara-C-treated animals still demonstrated varying degrees of immaturity with persistent disorganization at doses higher than $3 \mathrm{mg} / \mathrm{kg}$ (Fig. 3C3). Purkinje cells remained aberrant and small clusters and rows of ectopic cells were present within the molecular layer. At only the lowest dose of Ara-C $(3 \mathrm{mg} / \mathrm{kg})$ was there enough repair to approach normal cytoarchitecture at 22 days and still there was immaturity.

Behavioral and developmental observations largely confirmed the histopathology. Animals were observed qualitatively and quantitatively for activity, resting tremor, hind foot dragging, ataxia, and falling. After the 3 rd postnatal week, all of the Ara-A and Ara-Hx-treated animals, as well as animals treated with $3 \mathrm{mg} / \mathrm{kg}$ Ara-C, were normal in their development and behavior at this stage of maturation and could not be differentiated from control animals. The animals receiving $5-10 \mathrm{mg} / \mathrm{kg}$ Ara-C were markedly different from controls. Those which survived developed conspicuous ataxia, hind leg dragging, and "circling." These findings seemed to be more severe relative to increase in dose. In addition, all survivors in 
the $10 \mathrm{mg} / \mathrm{kg}$ group were runted, hairless, and showed signs of skin infection.

\section{DISCUSSION}

Cerebellogenesis follows similar patterns in all mammals and birds (9). There are subtle differences in the development of the external granular layer, in interneural and Purkinje cell maturation, and in the growth rate in different parts of the cerebellum, among genera. In the primate, including the human, in contrast to the rodent, most of these phenomena occur months earlier and the period of most rapid growth occurs before birth $(23,24)$. Thus, the danger of using drugs that suppress DNA replication in the newborn infant may be diminished but absolutely not eliminated. Certainly, the possibility of such damage would favor the use of nontoxic compounds where there is a choice. Such reasoning would have more importance in the treatment of infections when they have developed in premature infants, when human cerebellar growth may be more sensitive to anti-DNA replicative activity.

These experiments have demonstrated obvious differences in the effect of two arabinosyl purines and an arabinosyl pyrimidine on the growth and development of newborn rats. Ara-A, given in excess of prevailing clinical doses (6) had no apparent effect in the rat on mortality, body growth, cerebellogenesis, and behavior, in comparison with salineinjected controls. Neither did Ara-Hx. The importance of using Ara-Hx in these experiments is in demonstrating that neither Ara-A nor its deaminated metabolite had a demonstrable anti-DNA replicative effect. If Ara-A had demonstrated effect and Ara-Hx had not, at equal doses, it could be assumed that Ara-A was not completely deaminated in tissues. If both had demonstrated anti-DNA replicative effect, then the molecular form responsible for such activity could have been either Ara-A or Ara-Hx or Ara- $\mathrm{Hx}$ alone, depending upon rate of tissue deamination.

Also, Ara-Hx has been shown to have anti-DNA viral activity in vitro (16). Because of the rapid deamination in vivo of Ara-A to Ara-Hx, it was important also to examine it for toxicity, and to find it lacking.

In marked contrast, when measured by the same parameters, Ara-C had profound effects which resulted in lack of development, permanent neurologic damage, and high mortality. It is important to note that these effects were observed at $5-10 \mathrm{mg} / \mathrm{kg}$ doses of Ara-C. Such doses regularly result in suppression of bone marrow $(12,15,22)$ and immune response (17). These doses have been used to treat viral infections in neonates $(12,15,22)$.

A similar situation may exist in respect to systemic viral chemotherapy with iododeoxyuridine (IUDR) in which the viral inhibiting dose may suppress cellular replication and produce serious toxicity $(3,5,20)$.

The potential of damage to the rapidly developing central nervous system by Ara-C, IUDR and FUDR and other similar drugs is obvious. However, without any available substitutes, Ara-C and IUDR have been used regularly in therapy of Herpes virus hominis and cytomegalovirus infection in neonates. No drug-induced central nervous system damage has been reported to date. However, the background of central nervous system damage in such patients is high; therefore, specific associations between chemotherapeutic agents (drugs) and neuropathologic disorders are difficult to make.

Ara-A is much less toxic than Ara-C. In vitro, toxicity to the stable L cells (mouse fibroblasts) (21) and to cultured human leukocytes $(11,19)$ is of the order of $1 / 100$ th that of Ara-C. It has been shown previously that doses of Ara-A much in excess of those used in these experiments produced only mild toxicity, primarily reversible weight loss, in adult small animals (13). To date, at doses between 5 and $20 \mathrm{mg} / \mathrm{kg} / 24 \mathrm{hr}$, the human toxicity of Ara-A has been limited to nausea and lack of weight gain during intravenous infusion (6). No serious toxicity has been encountered from courses of therapy extending over 14-21-day periods in children or adults (6). At 5-10 times prevailing antiviral therapeutic doses, Gottlieb (10) has observed definite marrow suppression in patients under treatment for leukemia. Here again, Ara-A is much less toxic than Ara-C.

Therefore, Ara-A, if proven to be a clinically effective antiviral drug, may offer a choice in chemotherapy of large DNA viral infections. In any case, long term follow-up of treated neonates and young infants, particularly those who receive toxic drugs, must be compared with untreated patients, or to patients receiving presumptively nontoxic antiviral compounds. If Ara-A is effective in suppressing DNA viral infections in neonates, then an opportunity is provided to make a direct comparison between presumptively effective antiviral compounds, one of which has no known human toxicity at prevailing doses. Only in this manner will one be able to ascertain whether or not toxic antiviral compounds result in further damage in patients in whom the spectrum of sequelae is already broad as a result of the infection.

\section{SUMMARY}

Newborn rats treated with arabinosides of purine and pyrimidine were examined for growth, development, and neurologic abnormalities as well as growth, maturation, and cellular organization of the cerebellum; Ara-A, Ara-Hx, and saline-injected animals were normal, whereas Ara-C-injected animals frequently died and survivors had histologic as well as gross abnormalities.

\section{REFERENCES AND NOTES}

1. Altman, J.: Postnatal neurogenesis and the problem of neural plasticity. In: W. Himwich: Developmental Neurobiology, pp. 197-237 Charles C Thomas, Springfield, Ill. (1970).

2. Altman, J., Anderson, W. J., and Strop, M.: Retardation of cerebellar and motor development by focal $x$-irradiation during infancy. Physiol. Behav. 7: 143 (1971).

3. Breedan, C. J., Hall, T. C., and Tyler, H. R.: Herpes simplex encephalitis treated with systemic 5-iodo-2'-deoxyuridine. Ann Intern. Med., 65: 1050 (1966).

4. Brink, J. J., and Lepage, G. A.: Metabolism and distribution of 9- $\beta$-D-Arabinofuranosyladenine in mouse tissues. Cancer Res., 24: 1042 (1964)

5. Calabresi, P.: Current status of clinical investigation with 6-azauridine, 5-iodo- $2^{\prime}$-deoxyuridine and related derivatives. Cancer Res. 23: $1260(1963)$

6. Ch'ien, L. T., Schabel, F. M., Jr., and Alford, C. A., Jr.: Arabinosyl nucleosides and nucleotides. In: W. A. Carter: Selective Inhibitors of Viral Functions, p. 227 (CRC Press, Cleveland, 1973).

7. Cooper, G. M.: Phosphorylation of 5-bromodeoxycytidine in cells infected with Herpes simplex virus. Proc. Nat. Acad. Sci. U. S. A., $70: 3788$ (1973).

8. Fisher, D. S., and Jonas, A. M.: Cerebellar hypoplasia resulting from cytosine arabinoside treatment in the neonatal hamster. Clin. Res., 13: 540 (1965).

9. Fujita, S.: Autoradiographic studies on histogenesis of the cerebellar cortex. In: R. Llinas: Neurobiology of cerebellar evolution and development, pp. 743-747 (American Medical Association, Chicago, 1969).

10. Gottlieb, J. A., and Bodey, G. P.: Possible bone marrow depression by Ara-A therapy for disseminated Herpes zoster. N. Engl. J. Med., 290: 914 (1974).

11. Kihlman, B. A., Nichols, W. W. and Levan, A. The effect of deoxyadenosine and cytosine arabinoside on the chromosomes of human leukocy tes in vitro. Hereditas, 50: 139 (1963).

12. Kraybill, E. N., Sever, J. L., Avery, G. B., and Movassaghi, N. Experimental use of cytosine arabinoside in congenital cytomegalovirus infection. J. Pediat., 80: 485 (1972).

13. Kurtz, S. M., Fisken, R. A., Kaump, D. H., and Schardein, J. L. Toxicity of $9-\beta-D$-arabinofuranosyladenine in mice and rabbits. Antimicrob. Agents Chemother., 180 (1968-1969).

14. Langman, J., Shimada, M., and Rodier, P.: Floxuridine and its influence on postnatal cerebellar development. Pediat. Res., 6: 758 (1972).

15. Mccracken, G. H., Jr., and Luby, J. P.: Cytosine arabinoside in the 
treatment of congenital cytomegalic inclusion disease. J. Pediat. 80: 488 (1972).

16. Miller, F. A., Dixon, G. J., Ehrlich, J., et al: Antiviral activity of 9- $\beta$-D-Arabinofuranosyladenine. 1 . Cell culture studies. Antimicrob. Agents Chemother., 136 (1968).

17. Mitchell, M. S., Wade, M. E., Deconti, B. C., Bertino, J. R., and Calabresi, P.: Immunosuppressive effects of cytosine arabinoside and methotrexate in man. Ann. Intern. Med., 70: 535 (1969).

18. Nathanson, N., Cole, G. A. and van Der Loos, H.: Heterotopic cerebellar granule cells following administration of cyclophosphamide to suckling rats. Brain Res., 15: 532 (1969).

19. Nichols, W. W.: In vitro chromosome breakage induced by arabinosyladenine in human leukocytes. Cancer Res., 24: 1502 (1964).

20. Nolan, D. C., Carruthers, M. M., and Lerner, A. M.: Herpesvirus hominis encephalitis in Michigan. N. Engl. J. Med., 282: 10 (1970).

21. Ortiz, P. J., Manduka, M. J., and Cohen, S. S.: The lethality of some D-Arabinosyl nucleotides to mouse fibroblasts. Cancer Res., 32: 1512 (1972).

22. Plotkin, S. A., and Stetler, H.: Treatment of congenital cytomegalic inclusion disease with antiviral agents. Antimicrob. Agents Chemother., 373 (1969-1970).

23. Raaf, J., and Kernohan, J. W.: A study of the external granular layer in the cerebellum. Amer. J. Anat., 75: 151 (1944).

Copyright $\odot 1974$ International Pediatric Research Foundation, Inc.
24. Rakic, P., and Sidman, R. L.: Histogenesis of cortical layers in human cerebellum, particularly the lamina dessicans. J. Comp. Neurol., 139: 473 (1970).

25. Schabel, F. M., Jr.: The antiviral activity of 9- $\beta$-D-arabinofuranosyladenine (Ara-A). Chemotherapy, 13: 321 (1968).

26. Wallace, R. B., and Altman, J.: Behavioral effects of neonatal irradiation of the cerebellum. I. Qualitative observations in infants and adolescent rats. Develop. Psychobiol., 2: 257 (1969).

27. Woodward, D. J., Hoffer, B. J., and Lapham, L. W.: Correlative survey of the electrophysiological, neuropharmacological and histochemical aspects of cerebellar maturation in rats. In: $R$. Llinas: Neurobiology of cerebellar evolution and development, pp. 725-741 (American Medical Association, Chicago, 1969).

28. The Upjohn Co., Los Angeles, Calif.

29. Kindly supplied by Parke-Davis \& Co., Ann Arbor, Mich.

30. Kindly supplied by Dr. F. Kung, University Hospital of San Diego County, San Diego, Calif.

31. This work was supported by a grant from Parke-Davis \& Co., Ann Arbor, Michigan, and Grant no. NS09053 from the National Institutes of Health, Bethesda, Md.

32. Requests for reprints should be addressed to: J. D. Connor, M.D., Department of Pediatrics, University of California, San Diego, P. O. Box 109, La Jolla, Calif. 29037 (USA).

33. Accepted for publication May $30,1974$. 